\title{
Short communication: Ketosis, feed restriction, and an endotoxin challenge do not affect circulating serotonin in lactating dairy cows
}

\author{
E. A. Horst, S. K. Kvidera, M. Abuajamieh, E. J. Mayorga, M. Al-Qaisi, and L. H. Baumgard* \\ Department of Animal Science, lowa State University, Ames 50011
}

\section{ABSTRACT}

Circulating serotonin (5-hydroxytryptamine; 5-HT) appears to be associated with various energetic disorders and hypocalcemia during the transition period. The objective of this study was to evaluate the effects of ketosis, feed restriction (FR), and endotoxin challenge (models in which energetic and calcium metabolism are markedly altered) on circulating 5-HT in lactating Holstein cows. Blood samples were obtained from 3 separate experiments; circulating $\beta$-hydroxybutyrate (BHB), nonesterified fatty acids (NEFA), and glucose were measured in all 3 experiments, whereas ionized calcium $\left(\mathrm{iCa}^{2+}\right)$ was measured only in the endotoxin challenge. In the ketosis study, blood samples from cows clinically diagnosed with ketosis $(\mathrm{n}=9)$ or classified as healthy $(\mathrm{n}=9)$ were obtained from a commercial dairy farm at $\mathrm{d}-7,3$, and 7 relative to calving. Ketosis was diagnosed using a urine-based test starting at $5 \mathrm{~d}$ in milk. There was no effect of health status on circulating 5-HT and no association between 5-HT and BHB, NEFA, or glucose; however, 5-HT concentrations progressively decreased following calving. In the FR experiment, mid-lactation cows were either fed ad libitum $(\mathrm{n}=3)$ or restricted to $20 \%$ of their ad libitum intake $(\mathrm{n}=5)$ for $5 \mathrm{~d}$. There were no FR effects on circulating 5-HT, nor was FR correlated with energetic metabolites. In the immune activation model, mid-lactation cows were intravenously challenged with either lipopolysaccharide (LPS; $1.5 \mu \mathrm{g} / \mathrm{kg}$ of $\mathrm{BW} ; \mathrm{n}=6$ ) or sterile saline (control; $\mathrm{n}=6$ ). Administering LPS decreased (56\%) blood $\mathrm{iCa}^{2+}$ but had no effect on circulating 5 -HT, nor was there a correlation between circulating 5 -HT and NEFA, BHB, or $\mathrm{iCa}^{2+}$. Circulating 5-HT tended to be positively correlated $(\mathrm{r}=0.54)$ with glucose in Holstein cows administered LPS. In summary, in contrast to expectations, circulating 5-HT was unaffected in models of severely disturbed energetic and $\mathrm{Ca}^{2+}$ homeostasis. Key words: periparturient, milk fever, calcium

Received June 13, 2019

Accepted August 20, 2019.

*Corresponding author: baumgard@iastate.edu

\section{Short Communication}

Serotonin (5-hydroxytryptamine; 5-HT), a neurotransmitter derived from tryptophan, is synthesized by the central nervous system (CNS) and peripherally by cell types including enterochromaffin cells of the gastrointestinal tract (Gershon et al., 1965) and mammary epithelial cells (Berger et al., 2009; El-Merahbi et al., 2015). In laboratory animals, the majority (>90\%) of 5 -HT is produced by enterochromaffin cells and carried by platelets, which release it following activation (Berger et al., 2009). Serotonin is involved in multiple organ and physiological systems (Berger et al., 2009) and has gained considerable attention for its apparent role in lactation (Hernandez et al., 2008; Pai and Horseman, 2008; Collier et al., 2012; Hernandez, 2018). In particular, 5-HT was first identified as a key homeostatic regulator of lactation and involution (Matsuda et al., 2004; Collier et al., 2012). Additionally, 5-HT is related to periparturient calcium (Ca) levels (Laporta et al., 2015; Weaver et al., 2016; Hernández-Castellano et al., 2017a,b) and energetics (Laporta et al., 2013a; Laporta and Hernandez, 2015; Moore et al., 2015). Although less established in livestock species (HernándezCastellano et al., 2018), 5-HT seems to also act as an immune modulator (Baganz and Blakely, 2013; Duerschmied et al., 2013). Consequently, 5-HT has practical implications for multiple variables in the periparturient dairy cow.

The transition into lactation is characterized by significant hormonal, metabolic, mineral, and immunological changes, which are normal and necessary to support the new dominant physiological state (Bauman and Currie, 1980; Baumgard et al., 2017). However, maladaptation to lactation increases the risk of metabolic disorders (i.e., ketosis, hypocalcemia), which acutely and chronically compromise profitability (Coleman et al., 1985; McArt et al., 2012). It is of interest to identify strategies that may improve animal health and farm profitability during this period. Therefore, the objective of this study was to investigate whether circulating 5-HT concentrations are altered in models of severe metabolic and mineral perturbation, as these 
results may determine whether 5 -HT could serve as a potential target molecule with therapeutic utility.

All procedures were approved by the Iowa State University Institutional Animal Care and Use Committee. Subsets of cows were chosen from 3 separate studies. Experiment 1 was an observational study in which periparturient multiparous Holstein cows (parity $3.5 \pm 0.9$; housed on a commercial dairy) were retrospectively categorized into 1 of 2 groups: (1) healthy cows not diagnosed with any illnesses or (2) clinically diagnosed ketotic cows with no other overt health disorder (Abuajamieh et al., 2016). Nine cows were diagnosed with ketosis ( $>15 \mathrm{mg} / \mathrm{dL}$ urine acetoacetate) using a urine-based test (Ketostix, Bayer Health Care LLC, Mishawaka, IN) starting at 5 DIM. Each of the ketotic cows were paired with 9 healthy cows calving at approximately the same time. Serum samples were collected via coccygeal venipuncture into silicone-coated Vacutainers containing a silica act clot activator (BD, Franklin Lakes, NJ) on d $-7,3$, and 7 ( \pm 3 DIM) relative to calving.

Experiment 2 used 8 lactating Holstein cows (157 \pm 9 DIM, $713 \pm 10 \mathrm{~kg}$ of BW, parity 2 to 4) housed in individual box stalls $(4.57 \times 4.57 \mathrm{~m})$ at the Iowa State University Dairy Farm (Kvidera et al., 2017b). Following $5 \mathrm{~d}$ of baseline data collection (period $1 ; \mathbf{P 1}$ ), cows were allocated to 1 of 2 feed restriction $(\mathbf{F R})$ treatments: (1) ad libitum feed intake (AL; $\mathrm{n}=3$ ) or (2) $20 \%$ of P1 feed intake (FR; $\mathrm{n}=5$ ). Daily feed intake during period 2 (P2) was determined by applying the desired percentage (100 or 20\%) of FR to each cow's mean daily intake during $\mathrm{P} 1$. The calculated amount of feed was divided into 3 equal portions during P2 (0800, 1300 , and $1800 \mathrm{~h}$ ) in order to minimize metabolic variation due to gorging. Blood samples were collected on d 4 of P1 and d 5 of P2 at $1730 \mathrm{~h}$ before milking and feeding and were distributed equally between a tube containing $50 \mu \mathrm{L}$ of sterile heparin (Sagent Pharmaceuticals, Schaumburg, IL) and an empty glass tube (for serum collection).

Experiment 3 used 12 Holstein cows $(718 \pm 16 \mathrm{~kg}$ of BW; $169 \pm 7$ DIM; parity 2 or 3 ) that were housed at the Iowa State University Dairy Farm as previously described (Kvidera et al., 2017a). Cows were randomly assigned to 1 of 2 intravenous bolus treatments: (1) control (Control; $3 \mathrm{~mL}$ of sterile saline; $\mathrm{n}=6$ ) or $(2)$ LPS $(1.5 \mu \mathrm{g}$ of LPS $/ \mathrm{kg}$ of BW; $\mathrm{n}=6)$. Feed was removed approximately $1 \mathrm{~h}$ before treatment administration, and animals remained fasted during the 720-min data collection period. Blood samples were obtained 0 , 360 , and 720 min post-LPS infusion and were distributed equally between a tube containing K2EDTA (for plasma collection; BD) and an empty glass tube (for serum collection). Blood ionized $\mathrm{Ca}\left(\mathbf{i C a}^{2+}\right)$ was measured using an i-STAT handheld machine and cartridge (CG8+; Abbott Point of Care, Princeton, NJ).

Serum and plasma from all 3 experiments were harvested following centrifugation at $1,500 \times g$ for $15 \mathrm{~min}$ at $4^{\circ} \mathrm{C}$ and were subsequently frozen at $-20^{\circ} \mathrm{C}$ until analysis. Analyses of nonesterified fatty acids (NEFA), glucose, and BHB are described in each respective paper. Serum 5-HT was determined using a commercially available kit according to the manufacturer's instructions (Beckman Coulter Immunotech, Marseille, France) as previously described (Laporta and Hernandez, 2015; Moore et al., 2015); inter- and intra-assay coefficients of variation were 9.1 and $7.2 \%$, respectively.

Each animal's respective parameter was analyzed using repeated measures autoregressive covariance or spatial power law structure. The repeated effect was time (day for the transition cow study and minute for the endotoxin challenge study), and the random effect was cow. Effects of treatment, time, and treatment $\times$ time interaction were assessed as a completely randomized design using PROC MIXED (SAS Institute Inc., Cary, NC). Correlation analysis was evaluated using PROC CORR for 5-HT versus NEFA, glucose, BHB, and $\mathrm{iCa}^{2+}$ (LPS study only) during P2.

In the transition cow study, compared with prepartum levels, circulating 5 -HT progressively decreased postpartum (57 and $62 \%$ on d 3 and 7 postpartum, respectively; $P=0.01$; Figure $1 \mathrm{~A}$ ). However, despite the stark difference in metabolic state, there were no health status (ketotic vs. healthy) differences in 5-HT concentrations $(P>0.74$; Figure $1 \mathrm{~A})$. In the FR experiment, circulating 5 -HT was not altered following 5 d of severe FR $(P>0.96$; Figure $1 \mathrm{C})$. In the endotoxin trial, LPS administration induced severe hypocalcemia (46\%), but there was no LPS effect on circulating 5-HT concentrations $(P>0.56$; Figure $1 \mathrm{~B})$. No correlations were observed between 5-HT and NEFA or BHB in any of the experiments or $\mathrm{Ca}^{2+}$ in the LPS infusion trial (Figure 2A-C; Figure 3A, C, D). However, there was a tendency for a positive correlation between glucose and 5 -HT in LPS-administered cows $(P=0.07 ; \mathrm{r}=0.54$; Figure 3B).

Evidence suggests that 5-HT functions as a homeostatic regulator of lactation. Serotonin concentrations change dynamically throughout lactation and are thought to govern seemingly distinctly different biological processes, including mammary gland involution, energy balance, and Ca homeostasis (Matsuda et al., 2004; Hernandez et al., 2011; Laporta et al., 2013a,b, 2015; Laporta and Hernandez, 2015; Moore et al., 

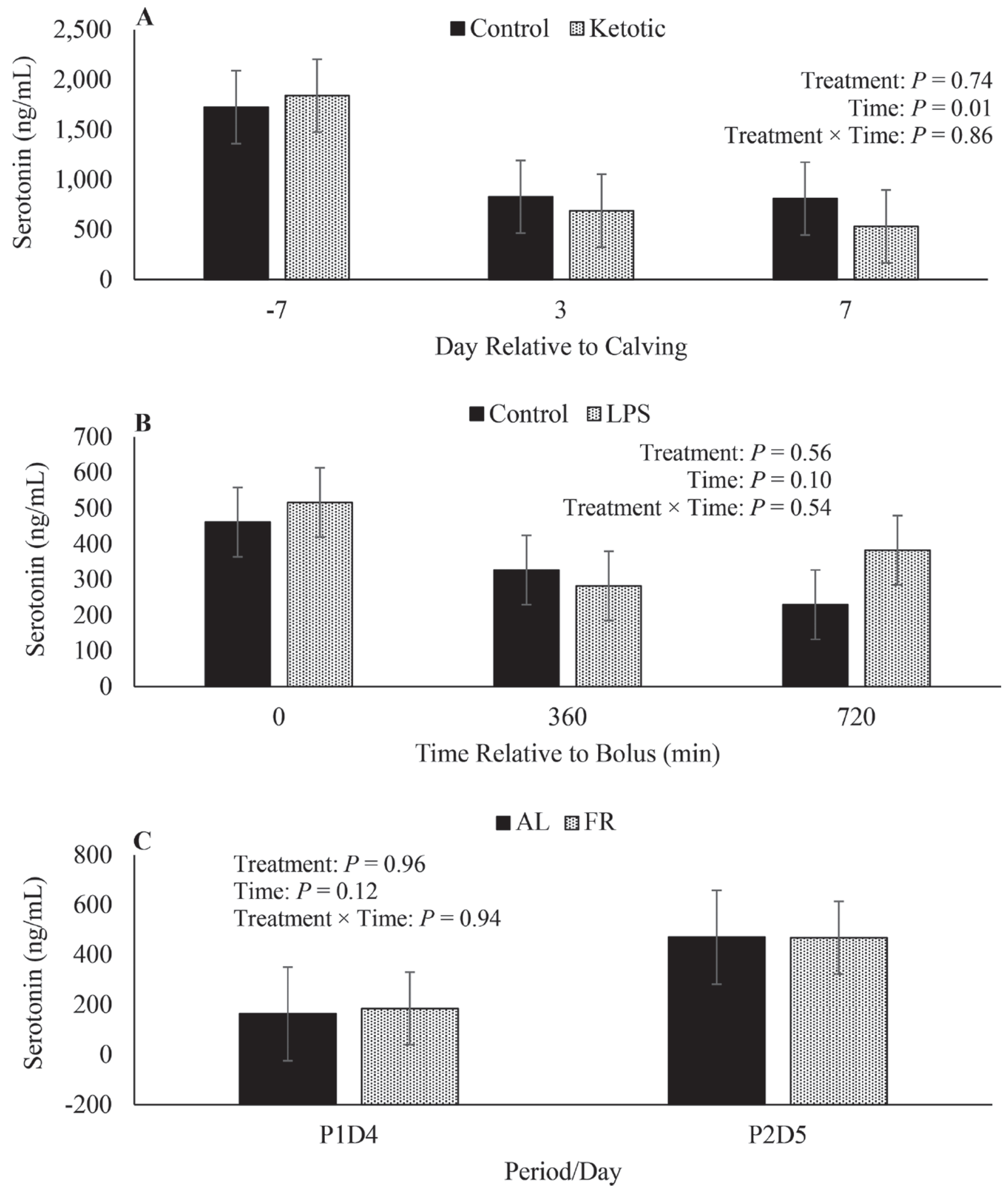

Figure 1. Effects of (A) ketosis, (B) an LPS bolus, and (C) feed restriction on circulating serotonin in Holstein cows. Data are reported as $\mathrm{LSM} \pm \mathrm{SEM}$. Panel A: Ketotic = cows diagnosed with clinical ketosis starting at 5 DIM, using a urine-based test; Control = healthy cows not diagnosed with a health disorder. Panel B: Control = cows intravenously infused with sterile saline; LPS = cows intravenously infused with lipopolysaccharide $(1.5 \mu \mathrm{g} / \mathrm{kg}$ of BW). Panel C: $\mathrm{AL}=$ cows fed ad libitum; $\mathrm{FR}=$ feed-restricted cows. 
$\bullet$ Control $\Delta$ Ketotic
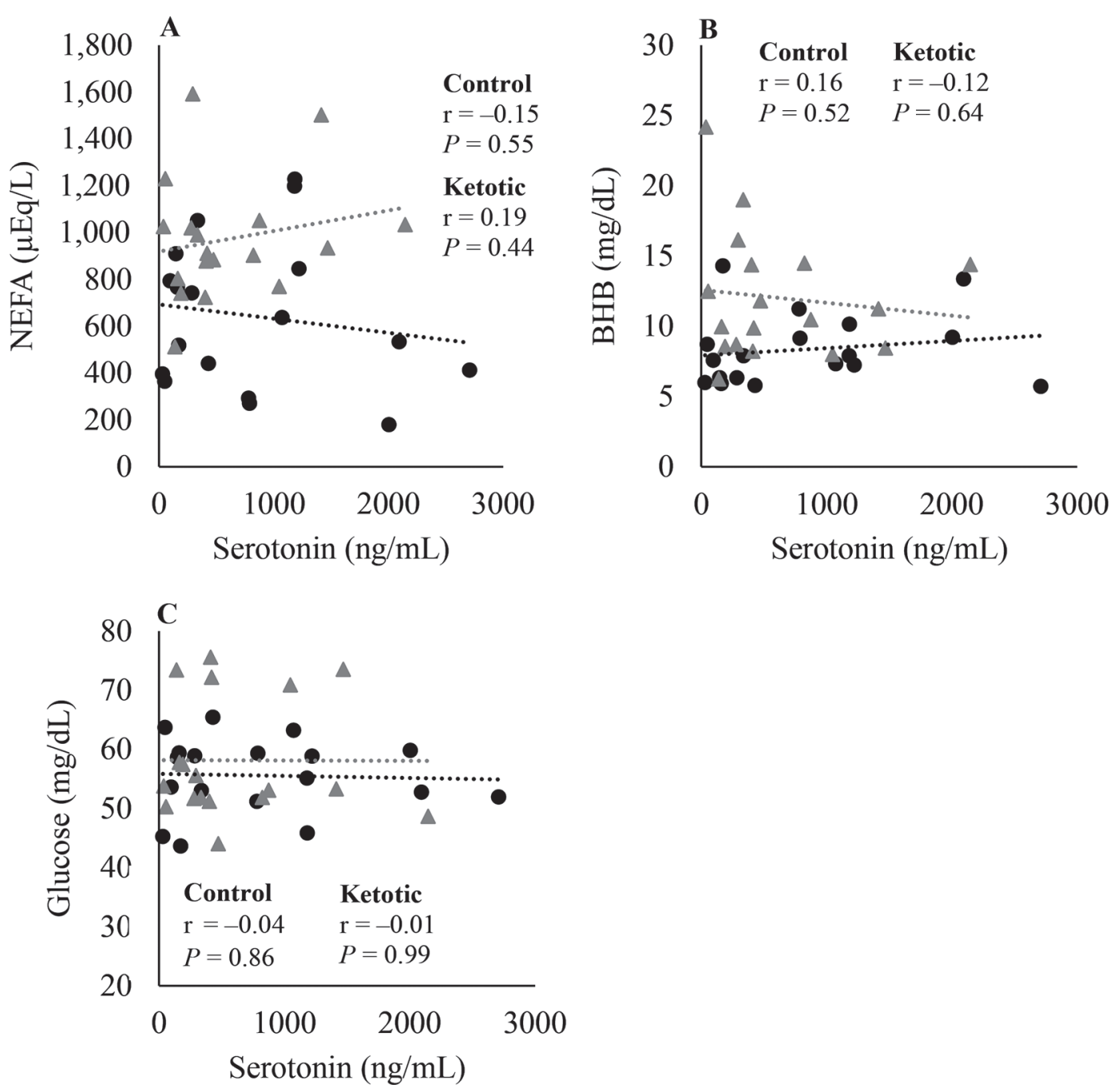

Figure 2. Correlation of circulating serotonin and (A) nonesterified fatty acids (NEFA), (B) BHB, and (C) glucose in clinically ketotic (gray triangles) or healthy (black circles) Holstein cows. Ketotic $=$ cows diagnosed with clinical ketosis starting at 5 DIM, using a urine-based test. Control = healthy cows not diagnosed with a health disorder.

2015). In agreement with previous literature (Laporta and Hernandez, 2015; Moore et al., 2015), we observed a temporal change in circulating 5 -HT following parturition, ostensibly reflecting the dual manner in which 5 -HT regulates mammary epithelial cell tight junction permeability during lactation and involution (Stull et al., 2007; Pai and Horseman, 2008). High concentrations of 5-HT in cell culture are thought to inhibit milk protein synthesis and induce mammary epithelial cell apoptosis (Pai and Horseman, 2008, 2011; Hernandez et al., 2011), a scenario contributing to milk synthesis cessation. Further, increased circulating 5-HT concentrations postpartum are associated with lower milk yield and increased SCC (Kessler et al., 2018, 2019).
Therefore, the concentration and temporal pattern of circulating 5-HT are thought to largely influence its function within the mammary gland.

Several reports suggest a role of 5-HT in regulating glucose and lipid metabolism in rodents (Watanabe et al., 2011; Laporta et al., 2013b), dogs (Moore et al., 2004, 2005), and ruminants (Watanabe et al., 2014; Laporta et al., 2015; Hernández-Castellano et al., 2017a). Infusing 5-HT or 5-hydroxy-L-tryptophan (5-HTP; a serotonin precursor) has been shown to increase insulin secretion (Sugimoto et al., 1990), stimulate hepatic glycogenesis (Hampson et al., 2007), increase mRNA abundance of hepatic gluconeogenic enzymes, and increase mammary glucose transporters (Laporta et 
al., 2013b, 2015). In lactating cows, infusing 5-HTP altered circulating markers of energy metabolism, including increasing glucose and NEFA and decreasing BHB (Laporta et al., 2015), although this has not been corroborated (Hernández-Castellano et al., 2017b; Weaver et al., 2017). Furthermore, endogenous 5 -HT levels have also been shown to be affected by or correlated with fasting and ketosis severity, respectively (Sumara et al., 2012; Laporta et al., 2013a). The aforementioned increase in gluconeogenic capacity and mammary glucose uptake (ostensive variables associated with increased milk synthesis) following 5-HTP administration (Laporta et al., 2013b, 2015) seemingly contradicts the role of endogenous 5-HT in inhibiting milk synthesis (Hernandez et al., 2008, 2011; Kessler et al., 2019). Regardless, and in contrast to the aforementioned reports, we observed no treatment differences in 5-HT concentrations in the ketosis or FR study despite observing marked alterations in energetic metabolism (Abuajamieh et al., 2016; Kvidera et al., 2017b). In addition to not detecting treatment differences, we surprisingly observed no correlation between $5-\mathrm{HT}$ and glucose, NEFA, or BHB in the transition cow study. The relationship between 5-HT and glucose is variable, as negative (Moore et al., 2015) and positive (Laporta and Hernandez, 2015) correlations have been observed, whereas others have not detected a relationship (Laporta et al., 2013a; Kessler et al., 2018). Not observing an association between 5-HT and NEFA or BHB herein agrees with previous observations (Kessler et al., 2018).
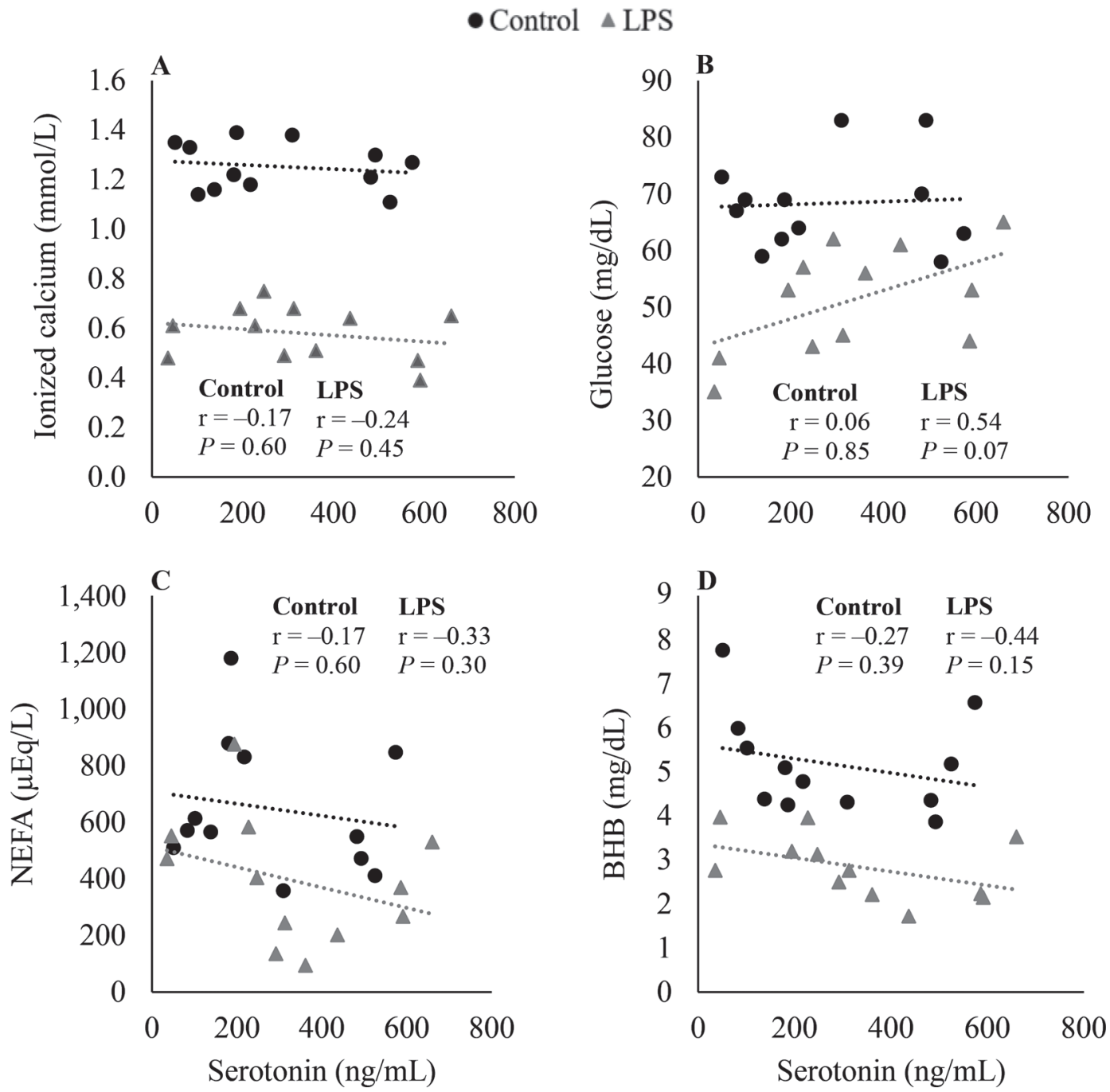

Figure 3. Effects of an LPS bolus (1.5 $\mu \mathrm{g}$ of LPS $/ \mathrm{kg}$ of BW; gray triangles) or saline bolus (3 $\mathrm{mL}$ of sterile saline; black circles) on the correlation of circulating serotonin and (A) ionized calcium, (B) glucose, (C) nonesterified fatty acids (NEFA), and (D) BHB in lactating Holstein cows. 
Inconsistencies in 5-HT's influence on metabolism may be partially explained by differences in infusion versus endogenous sources of 5 -HT, as endogenous sources may be insufficient to alter circulating metabolites; this agrees with Kessler et al. (2018). Further investigating the relationship between 5 -HT and energetics without exogenous manipulation is warranted.

In agreement with the transition cow and FR studies, we observed no change in 5-HT concentrations following LPS administration, but this disagrees with previous LPS reports (Emau et al., 1986; Endo and Nakamura, 1992). Administering LPS markedly decreases circulating platelets (Kvidera et al., 2017a), which store the majority of 5-HT and release it following activation (Lesurtel et al., 2006). Following LPS administration, platelets rapidly migrate to the presumed site of infection and are largely taken up by the liver. As a result, circulating 5-HT levels decrease and hepatic concentrations increase (Endo and Nakamura, 1992). Reasons for not observing LPS-induced changes in 5-HT concentrations despite observing thrombocytopenia are not entirely clear but warrant further investigation. Besides directly influencing the cells that store 5-HT, LPS markedly affects energetics and Ca homeostasis (Kvidera et al., 2017a), which we incorrectly hypothesized would alter 5 -HT concentrations. In addition to observing no LPS effects on circulating 5-HT, no relationship between 5-HT and NEFA or BHB was detected. However, 5 -HT tended to be positively correlated with glucose in the LPS-infused cows. Administering LPS induces a marked biphasic change in circulating glucose with an initial period of hyperglycemia followed by hypoglycemia (Kvidera et al., 2017a). Further assessing the effect of LPS administration on hepatic and circulating 5-HT concentrations and its relationship with hepatic glucose output has implications for transition cows.

In addition to energetic metabolism, 5-HT is purportedly an important regulator of $\mathrm{Ca}$ homeostasis (Hernandez et al., 2012; Laporta et al., 2013c; Hernández-Castellano et al., 2017a,b; Hernandez, 2018). The mammary gland has a large Ca demand at the onset of lactation and relies on proper hormonal regulation (i.e., increased parathyroid hormone and decreased calcitonin action) to maintain eucalcemia (Horst et al., 2005). However, mammary Ca uptake is so acute and extensive that it often exceeds homeostatic strategies employed to maintain eucalcemia (Goff, 2008) and clinical or subclinical hypocalcemia develops. Parathyroid hormone-related protein (PTHrP) is the primary hormone responsible for Ca mobilization during lactation (Wysolmerski et al., 1995; Wysolmerski, 2010), and several studies have observed a positive correlation between 5-HT and PTHrP (Laporta et al., 2013a) and 5-HT and Ca (Laporta et al., 2013a; Moore et al., 2015). Additionally, cows classified as having high 5-HT levels tended to have increased total Ca concentrations (Kessler et al., 2018). Oral 5-HTP supplementation increases circulating PTHrP and Ca, osteoclast number, and expression of $\mathrm{Ca}$ transporters in the rodent mammary gland (Laporta et al., 2013c, 2014), although results in ruminants are inconsistent (Laporta et al., 2015; Weaver et al., 2016; Hernández-Castellano et al., 2017a,b). Similar to early lactogenesis, LPS administration results in a severe and sustained hypocalcemia lasting $>24 \mathrm{~h}$ (Horst et al., 2018). Surprisingly, we did not observe a correlation between 5 -HT and $\mathrm{iCa}^{2+}$ concentrations in the present study. The reasons why we did not detect a relationship between severe hypocalcemia and 5-HT are unclear, but our model of immune activation is acute $(<24 \mathrm{~h})$ and periparturient hypocalcemia is chronic $(>1-3 \mathrm{~d})$.

In summary, the experiments presented herein caused marked alterations in energetic and $\mathrm{Ca}$ homeostasis, changes similar to a transitioning dairy cow, yet 5-HT concentrations were unaffected and no correlations were observed between 5-HT and NEFA, BHB, or $\mathrm{iCa}^{2+}$. The experimental models we used and implemented were admittedly severe and may have temporally overwhelmed the regulatory role of 5 -HT. Models that were less metabolically insulting and longer lasting may have produced a different interpretation. Regardless, the effects of 5-HT on energetic and Ca metabolism are incredibly variable, and the supposed causal role of 5-HT in common transition cow disorders needs a more thorough and critical evaluation.

\section{ACKNOWLEDGMENTS}

The results described herein were supported in part by the Norman Jacobson Endowed Professorship.

\section{REFERENCES}

Abuajamieh, M., S. K. Kvidera, M. V. Sanz Fernandez, A. Nayeri, N. C. Upah, E. A. Nolan, S. M. Lei, J. M. DeFrain, H. B. Green, K. M. Schoenberg, W. E. Trout, and L. H. Baumgard. 2016. Inflammatory biomarkers are associated with ketosis in periparturient Holstein cows. Res. Vet. Sci. 109:81-85.

Baganz, N. L., and R. D. Blakely. 2013. A dialogue between the immune system and brain, spoken in the language of serotonin. ACS Chem. Neurosci. 4:48-63.

Bauman, D. E., and W. B. Currie. 1980. Partitioning of nutrients during pregnancy and lactation: A review of mechanisms involving homeostasis and homeorhesis. J. Dairy Sci. 63:1514-1529.

Baumgard, L. H., R. J. Collier, and D. E. Bauman. 2017. A 100-year review: Regulation of nutrient partitioning to support lactation. J. Dairy Sci. 100:10353-10366.

Berger, M., J. A. Gray, and B. L. Roth. 2009. The expanded biology of serotonin. Annu. Rev. Med. 60:355-366. 
Coleman, D. A., W. V. Thane, and R. A. Dailey. 1985. Factors affecting reproductive performance of dairy cows. J. Dairy Sci. 68:1793-1803.

Collier, R. J., L. L. Hernandez, and N. D. Horseman. 2012. Serotonin as a homeostatic regulator of lactation. Domest. Anim. Endocrinol. 43:161-170.

Duerschmied, D., G. L. Suidan, M. Demers, N. Herr, C. Carbo, A. Brill, S. M. Cifuni, M. Mauler, S. Cicko, M. Bader, M. Idzko, C. Bode, and D. D. Wagner. 2013. Platelet serotonin promotes the recruitment of neutrophils to sites of acute inflammation in mice. Blood 121:1008-1015.

El-Merahbi, R., M. Löffler, A. Mayer, and G. Sumara. 2015. The roles of peripheral serotonin in metabolic homeostasis. FEBS Lett. 589:1728-1734.

Emau, P., S. N. Giri, and M. L. Bruss. 1986. Comparative effects of smooth and rough Pasteruella hemolytica lipopolysaccharides on arachidonic acid, eicosanoids, serotonin, and histamine in calves. Circ. Shock 20:239-253.

Endo, Y., and M. Nakamura. 1992. The effect of lipopolysaccharide, interleukin-1 and tumour necrosis factor on the hepatic accumulation of 5-hydroxytryptamine and platelets in the mouse. Br. J. Pharmacol. 105:613-619.

Gershon, M. D., A. B. Drakontides, and L. L. Ross. 1965. Serotonin Synthesis and release from the myenteric plexus of the mouse intestine. Science 149:197-199.

Goff, J. P. 2008. The monitoring, prevention, and treatment of milk fever and subclinical hypocalcemia in dairy cows. Vet. J. 176:50-57.

Hampson, L. J., P. Mackin, and L. Agius. 2007. Stimulation of glycogen synthesis and inactivation of phosphorylase in hepatocytes by serotonergic mechanisms, and counter-regulation by atypical antipsychotic drugs. Diabetologia 50:1743-1751.

Hernandez, L. L. 2018. A role for serotonin in lactation physiologyWhere do we go from here? J. Dairy Sci. 101:5671-5678.

Hernandez, L. L., J. L. Collier, A. J. Vomachka, R. J. Collier, and N. D. Horseman. 2011. Suppression of lactation and acceleration of involution in the bovine mammary gland by a selective serotonin reuptake inhibitor. J. Endocrinol. 209:45-54.

Hernandez, L. L., K. A. Gregerson, and N. D. Horseman. 2012. Mammary gland serotonin regulates parathyroid hormone-related protein and other bone-related signals. Am. J. Physiol. Endocrinol. Metab. 302:E1009-E1015.

Hernandez, L. L., C. M. Stiening, J. B. Wheelock, L. H. Baumgard, A. M. Parkhurst, and R. J. Collier. 2008. Evaluation of serotonin as a feedback inhibitor of lactation in the bovine. J. Dairy Sci. 91:1834-1844

Hernández-Castellano, L. E., L. L. Hernandez, H. Sauerwein, and R. M. Bruckmaier. 2017a. Endocrine and metabolic changes in transition dairy cows are affected by prepartum infusions of a serotonin precursor. J. Dairy Sci. 100:5050-5057.

Hernández-Castellano, L. E., L. L. Hernandez, S. Weaver, and R. M. Bruckmaier. 2017b. Increased serum serotonin improves parturient calcium homeostasis in dairy cows. J. Dairy Sci. 100:1580-1587.

Hernández-Castellano, L. E., R. Özçelik, L. L. Hernandez, and R. M. Bruckmaier. 2018. Short communication: Supplementation of colostrum and milk with 5-hydroxy-L-trytophan affects immune factors but not growth performance in newborn calves. J. Dairy Sci. 101:794-800.

Horst, E. A., S. K. Kvidera, E. J. Mayorga, C. S. Shouse, M. Al-Qaisi, M. J. Dickson, J. Ydstie, H. A. Ramirez Ramirez, A. F. Keating, D. J. Dickson, K. E. Griswold, and L. H. Baumgard. 2018. Effect of chromium on bioenergetics and leukocyte dynamics following immunoactivation in lactating Holstein cows. J. Dairy Sci. 101:5515-5530.

Horst, R. L., J. P. Goff, and T. A. Reinhardt. 2005. Adapting to the transition between gestation and lactation: Differences between rat, human and dairy cow. J. Mammary Gland Biol. Neoplasia 10:141-156.

Kessler, E. C., S. K. Wall, L. L. Hernandez, R. M. Bruckmaier, and J. J. Gross. 2018. Short communication: Circulating serotonin is related to the metabolic status and lactational performance at the onset of lactation in dairy cows. J. Dairy Sci. 101:11455-11460.

Kessler, E. C., S. K. Wall, L. L. Hernandez, J. J. Gross, and R. M. Bruckmaier. 2019. Short communication: Mammary gland tight junction permeability after parturition is greater in dairy cows with elevated circulating serotonin concentrations. J. Dairy Sci. 102:1768-1774.

Kvidera, S. K., E. A. Horst, M. Abuajamieh, E. J. Mayorga, M. V. Sanz Fernandez, and L. H. Baumgard. 2017a. Glucose requirements of an activated immune system in lactating Holstein cows. J. Dairy Sci. 100:2360-2374.

Kvidera, S. K., E. A. Horst, M. V. Sanz Fernandez, M. Abuajamieh, S. Ganesan, P. J. Gorden, H. B. Green, K. M. Schoenberg, W. E. Trout, A. F. Keating, and L. H. Baumgard. 2017b. Characterizing effects of feed restriction and glucagon-like peptide 2 administration on biomarkers of inflammation and intestinal morphology. J. Dairy Sci. 100:9402-9417.

Laporta, J., and L. L. Hernandez. 2015. Serotonin receptor expression is dynamic in the liver during the transition period in Holstein dairy cows. Domest. Anim. Endocrinol. 51:65-73.

Laporta, J., K. P. Keil, S. R. Weaver, C. M. Cronick, A. P. Prichard T. D. Crenshaw, G. W. Heyne, C. M. Vezina, R. J. Lipinski, and L. L. Hernandez. 2014. Serotonin regulates calcium homeostasis in lactation by epigenetic activation of hedgehog signaling. Mol Endocrinol. 28:1866-1874.

Laporta, J., S. A. E. Moore, M. W. Peters, T. L. Peters, and L. L. Hernandez. 2013a. Short communication: Circulating serotonin (5HT) concentrations on day 1 of lactation as a potential predictor of transition-related disorders. J. Dairy Sci. 96:5146-5150.

Laporta, J., S. A. E. Moore, S. R. Weaver, C. M. Cronick, M. Olsen, A. P. Prichard, B. P. Schnell, T. D. Crenshaw, F. Peñagaricano, R. M. Bruckmaier, and L. L. Hernandez. 2015. Increasing serotonin concentrations alter calcium and energy metabolism in dairy cows. J. Endocrinol. 226:43-55.

Laporta, J., T. L. Peters, K. E. Merriman, C. M. Vezina, and L. L. Hernandez. 2013b. Serotonin (5-HT) affects expression of liver metabolic enzymes and mammary gland glucose transporters during the transition from pregnancy to lactation. PLoS One 8:e57847.

Laporta, J., T. L. Peters, S. R. Weaver, K. E. Merriman, and L. L. Hernandez. 2013c. Feeding 5-hydroxy-L-tryptophan during the transition from pregnancy to lactation increases calcium mobilization from bone in rats. Domest. Anim. Endocrinol. 44:176-184.

Lesurtel, M., R. Graf, B. Aleil, D. J. Walther, Y. Tian, W. Jochum, C. Gachet, M. Bader, and P. A. Clavien. 2006. Platelet-derived serotonin mediates liver regeneration. Science 312:104-107.

Matsuda, M., T. Imaoka, A. J. Vomachka, G. A. Gudelsky, Z. Hou, M. Mistry, J. P. Bailey, K. M. Nieport, D. J. Walther, M. Bader, and N. D. Horseman. 2004. Serotonin regulates mammary gland development via an autocrine-paracrine loop. Dev. Cell 6:193-203.

McArt, J. A. A., D. V. Nydam, and G. R. Oetzel. 2012. Epidemiology of subclinical ketosis in early lactation dairy cattle. J. Dairy Sci. 95:5056-5066.

Moore, M. C., W. B. Geho, M. Lautz, B. Farmer, D. W. Neal, and A. D. Cherrington. 2004. Portal serotonin infusion and glucose disposal in conscious dogs. Diabetes 53:14-20.

Moore, M. C., K. Kimura, H. Shibata, T. Honjoh, M. Saito, C. A Everett, M. S. Smith, and A. D. Cherrington. 2005. Portal 5-hydroxytryptophan infusion enhances glucose disposal in conscious dogs. Am. J. Physiol. Endocrinol. Metab. 289:E225-E231.

Moore, S. A. E., J. Laporta, T. D. Crenshaw, and L. L. Hernandez. 2015. Patterns of circulating serotonin and related metabolites in multiparous dairy cows in the peripartum period. J. Dairy Sci. 98:3754-3765.

Pai, V. P., and N. D. Horseman. 2008. Biphasic regulation of mammary epithelial resistance by serotonin through activation of multiple pathways. J. Biol. Chem. 283:30901-30910.

Pai, V. P., and N. D. Horseman. 2011. Multiple cellular responses to serotonin contribute to epithelial homeostasis. PLoS One 6:e17028.

Stull, M. A., V. Pai, A. J. Vomachka, A. M. Marshall, G. A. Jacob, and N. D. Horseman. 2007. Mammary gland homeostasis employs 
serotonergic regulation of epithelial tight junctions. Proc. Natl. Acad. Sci. USA 104:16708-16713.

Sugimoto, Y., I. Kimura, J. Yamada, Y. Watanabe, N. Takeuchi, and K. Horisaka. 1990. Effects of serotonin on blood glucose and insulin levels of glucose- and streptozotocin-treated mice. Jpn. J. Pharmacol. 54:93-96.

Sumara, G., O. Sumara, J. K. Kim, and G. Karsenty. 2012. Gutderived serotonin is a multifunctional determinant to fasting adaptation. Cell Metab. 16:588-600.

Watanabe, H., M. T. Rose, and H. Aso. 2011. Role of peripheral serotonin in glucose and lipid metabolism. Curr. Opin. Lipidol. 22:186-191.

Watanabe, H., R. Saito, T. Nakano, H. Takahashi, Y. Takahashi, K. Sumiyoshi, X. Chen, N. Okada, S. Iwasaki, D. W. Harjanti, N. Sekiguchi, H. Sano, H. Kitazawa, M. T. Rose, S. Ohwada, K. Wantanabe, and H. Aso. 2014. Effect of peripheral 5-HT on glucose and lipid metabolism in wether sheep. PLoS One 9:e88058.

Weaver, S. R., A. P. Prichard, E. L. Endres, S. A. Newhouse, T. L. Peters, P. M. Crump, M. S. Akins, T. D. Crenshaw, R. M. Bruck- maier, and L. L. Hernandez. 2016. Elevation of circulating serotonin improves calcium dynamics in the peripartum dairy cow. J. Endocrinol. 230:105-123.

Weaver, S. R., A. S. Prichard, N. L. Maerz, A. P. Prichard, E. L. Endres, L. E. Hernández-Castellano, M. S. Akins, R. M. Bruckmaier, and L. L. Hernandez. 2017. Elevating serotonin pre-partum alters the Holstein dairy cow hepatic adaptation to lactation. PLoS One 12:e0184939.

Wysolmerski, J. J. 2010. Interactions between breast, bone, and brain regulate mineral and skeletal metabolism during lactation. Ann. N. Y. Acad. Sci. 1192:161-169.

Wysolmerski, J. J., J. F. McCaughern-Carucci, A. G. Daifotis, A. E. Broadus, and W. M. Philbrick. 1995. Overexpression of parathyroid hormone-related protein or parathyroid hormone in transgenic mice impairs branching morphogenesis during mammary gland development. Development 121:3539-3547. 